\title{
SENSORLESS VECTOR CONTROL OF BLDC USING EXTENDED KALMAN FILTER
}

\author{
Y.Lavanya $^{1 \mathrm{a}}$, N.P.G.Bhavani ${ }^{1 \mathrm{~b}}$, Neena Ramesh $^{2}$, K.Sujatha $^{3}$ \\ PG Student ${ }^{1 \mathrm{a}}$, Assistant Professor ${ }^{1 \mathrm{~b}}$, Professor $^{2,3}$ \\ 1a,1b,2Electrical and Electronics Department, \\ Meenakshi College of Engineering \\ Chennai, Tamil Nadu. \\ ${ }^{3}$ Dr .M.G.R. Educational and Research Institute, Chennai, Tamil Nadu, India \\ la lavanyay73 egmail. com \\ ${ }^{1 b}$ sbreddy9999@gmail. com
}

\begin{abstract}
This Paper mainly deals with the implementation of vector control technique using the brushless $D C$ motor (BLDC). Generally tachogenerators, resolvers or incremental encoders are used to detect the speed. These sensors require careful mounting and alignment, and special attention is required with electrical noises. A speed sensor need additional space for mounting and maintenance and hence increases the cost and size of the drive system. These problems are eliminated by speed sensor less vector control by using Extended Kalman Filter and Back EMF method for position sensing. By using the EKF method and Back EMF method, the sensor less vector control of BLDC is implemented and its simulation using MATLAB/SIMULINK and hardware kit is implemented.
\end{abstract}

\section{KEYWORDS}

Brushless DC Motor (BLDCM), Current controller, Extended kalman filter (EKF), Vector control.

\section{INTRODUCTION}

Permanent magnet AC motors has been classified in two categories: BLAC and BLDC. The first type has a sinusoidal current and back-EMF while the second's waveforms are rectangular. Brushless DC motor has good advantages such as large torque, high efficiency and high power density so that it has been used extensively in industries and is a appropriate motor for high performance applications [1]. Use of sensors for detection of position and speed is an important defect of control systems because of cost, weight and reduction of reliability. Many researches have been carried out for elimination of speed mechanical sensor. A wide variety of method has been proposed for speed estimation but kalman filter because of its good performance, has been used in drive systems [2]. The Kalman filter is an observer based on least square method and estimates system states optimally. The EKF has been derived from Kalman filter and used for

Sundarapandian et al. (Eds) : ITCCMA, FUZZY, SIGEM, DMDBS, NATL - 2015

pp. 43-55, 2015. ( CS \& IT-CSCP 2015

DOI : $10.5121 /$ csit.2015.50505 
nonlinear problems. This estimator has been applied to various motors [3]. In this paper, a novel scheme for EKF has been proposed. This paper develops to remove the drawbacks associated with sensored control and use of traditional controllers by using zero crossing point (ZCP) based on Back electromotive force (Back-EMF) sensorless control with fuzzy logic controller. The sensorless control requires good reliability and various speed ranges with the high starting torque for BLDC motor drive system. To satisfy these requirements, this paper proposes an efficient sensorless speed control to avoid high energy prices.

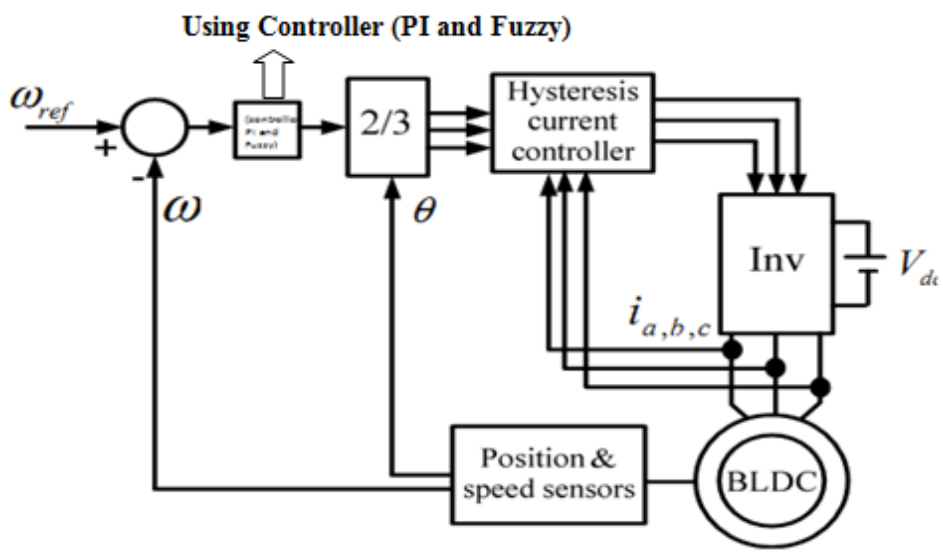

Fig 1:Block diagram.

\section{PRINCIPLES OF SENSORLESS BLDC MOTOR CONTROL}

BLDC motor drives have need of rotor position information for appropriate operation to execute phase commutation. Position sensors are generally used to provide the position information for the driver. So this type of position sensors is not used in sensorless drives. The advantage of sensorless drives comprises of less hardware cost, increased system reliability, decreased system size and reduced feedback units. And also they are free from mechanical and environmental constraints [2].

Various control methods arises for sensorless drive, in which a back-EMF is the most cost effective method to obtain the commutation sequence in the star wound motors and current sensing provides enough information to estimate with sufficient rotor position to drive the motor with synchronous phase currents. BLDC motor drives that do not require position sensors but it contains electrical dimensions are called a sensorless drive. The BLDC motor provides sensorless operation based on the nature of its excitation intrinsically suggest a low-cost way to take out rotor position information from motor-terminal voltages. In the excitation of a 3 phase BLDC motor, apart from the phase-commutation periods, two of the three phase windings are functioning at a time and no conducting phase carries in the back-EMF as shown in Fig. 1. Since back-EMF is zero at standstill and proportional to speed, the measured terminal voltage that has large signal-to-noise ratio cannot detect zero crossing at low speeds. That is the reason why in all back-EMF-based sensorless methods the low-speed performance is limited, and an open-loop starting strategy is required $[11,8]$. 


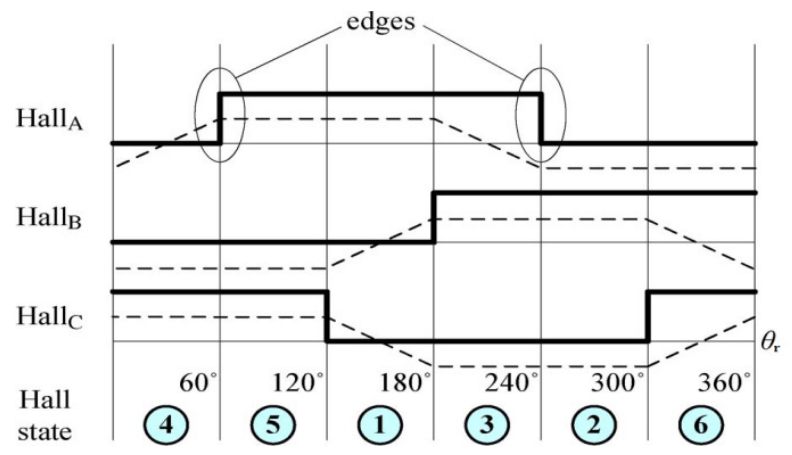

Fig. 2 (Thick solid line) Signals of the three phase Hall-effect sensors and (dotted line) ideal trapezoidal back EMF.

In BLDC motor the stator iron has a non-linear magnetic saturation features that is the fundamental from which it is feasible to find out the initial position of the rotor. When a stator winding is energized, then DC voltage is applied for a particular time and a magnetic field with a fixed direction will be recognized. Then, the stator current responses are changed owing to the inductance variation and this variation of the stator current responses which comprises of the information of the rotor position.

\section{A. Back-EMF Zero Crossing Detection Method}

The zero-crossing detection method is an easiest method of back-EMF sensing approach and it is based on finding the instantaneous at which unexcited phase crosses zero due to back-EMF [4]. This zero crossing activates a timer that might be as easy as an RC time constant; accordingly the next sequential inverter commutation take place at the end of timing interval.

For a distinctive operation of a BLDC motor, the back-EMF and phase current should be associated to generate constant torque. Fig. 2 shows the waveform for current commutation point which can be attained by the zero crossing point of back-EMFs and a six-step inverter commutation design for driving the BLDC motor [7,9].

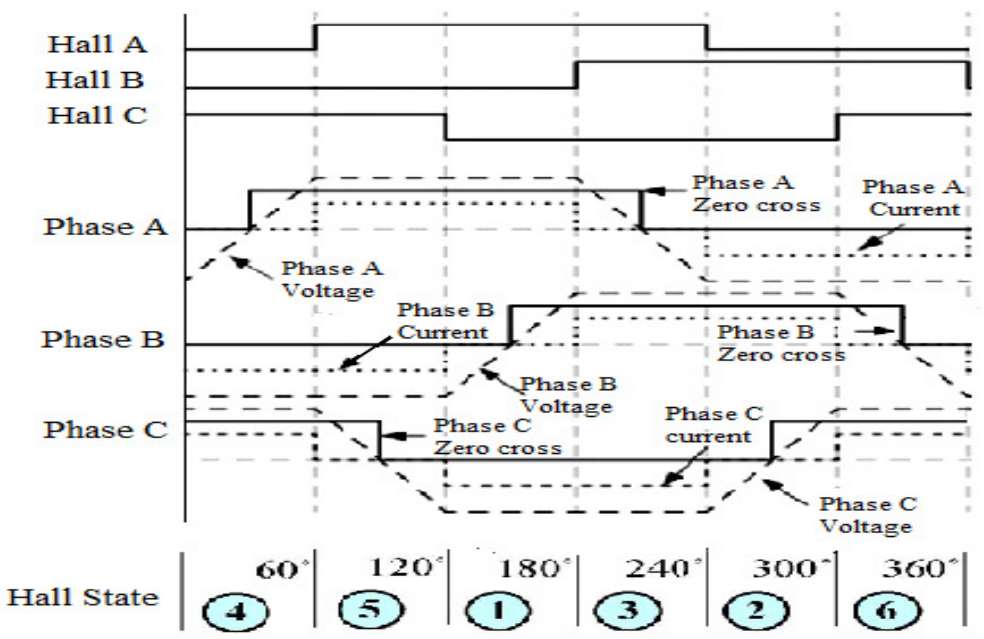

Fig. 3 Waveform of Back EMF and phase current with respect to Hall state. 
As a result the interval for every phase of a BLDC motor is conducted at 120 electrical degrees. Hence, in BLDC motor only two phases conduct current at whichever time. The third phase is called floating phase. In order to produce greatest torque, the inverter is to be commutated at every $60^{\circ}$ by calculating zero crossing of back-EMF on the floating phase of the motor, therefore the current is in phase with the back-EMF.

\section{MATHEMATICAL MODELLING OF BLDC MOTOR}

BLDC motor modelling is similar to three-phase synchronous machine modelling. The model is developed, in which the permanent magnet enclosed with the rotor and it contains different dynamic characteristics. Fig. 3 shows the Inverter BLDC motor-drive model. The BLDC motor is fed to a three-phase voltage source is not necessary to be sinusoidal or square wave can be applied. The peak voltage produced over there should not exceed the maximum voltage of the motor.

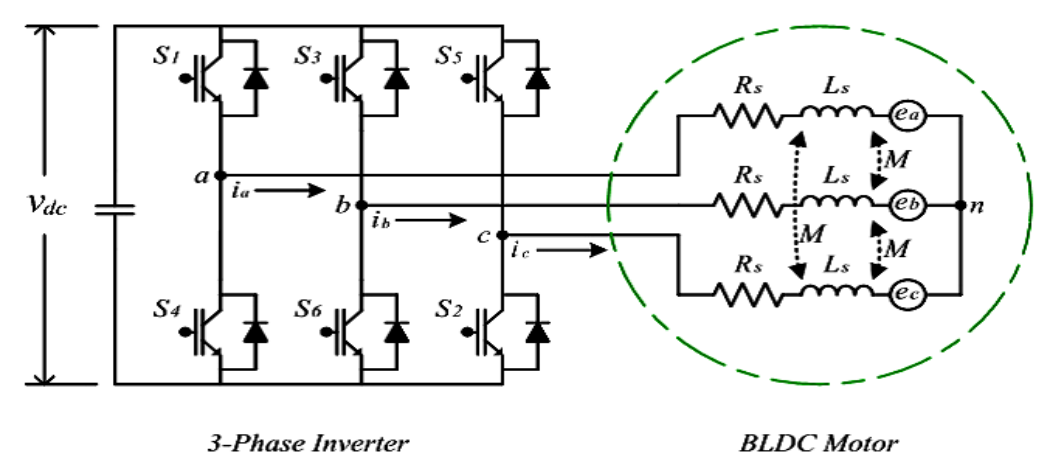

Fig. 4 Inverter with BLDC Motor drive model.

The fundamental model of the armature winding for the BLDC motor is defined as [3],

$$
\begin{aligned}
& V_{a}=R i_{a}+L \frac{d i_{a}}{d t}+e_{a} \\
& V_{b}=R i_{b}+L \frac{d i_{b}}{d t}+e_{b} \\
& V_{c}=R i_{c}+L \frac{d i_{c}}{d t}+e_{c}
\end{aligned}
$$

Where, $L$ and $R$ are the armature self-inductance $[H]$ and armature resistance $[\Omega]$ of the stator phase winding respectively, $\mathrm{Va}, \mathrm{V} b, \mathrm{Vc}$ are terminal phase voltage $[\mathrm{V}], i \mathrm{a}, i \mathrm{~b}, i \mathrm{c}$ are motor input current $[\mathrm{A}]$ and $e \mathrm{a}, e \mathrm{~b}, e \mathrm{c}$ are trapezoidal motor back emf [V] of respective phases.

Therefore the circuit equations of the three windings in phase variables are,

$$
\begin{aligned}
{\left[\begin{array}{l}
V_{a} \\
V_{b} \\
V_{c}
\end{array}\right]=\left[\begin{array}{lll}
R & 0 & 0 \\
0 & R & 0 \\
0 & 0 & R
\end{array}\right]\left[\begin{array}{l}
i_{a} \\
i_{b} \\
i_{c}
\end{array}\right]+\left[\begin{array}{ccc}
L_{a} & L_{a b} & L_{a c} \\
L_{b a} & L_{b} & L_{b c} \\
L_{c a} & L_{c b} & L_{c}
\end{array}\right] p\left[\begin{array}{l}
i_{a} \\
i_{b} \\
i_{c}
\end{array}\right] } & +\left[\begin{array}{l}
e_{a} \\
e_{b} \\
e_{c}
\end{array}\right]
\end{aligned}
$$


As it has been considered that motor is not saturated and negligible iron losses, the stator resistances of all the windings are equal, self-inductance are constant and mutual inductance are zero

$$
\begin{gathered}
L_{a}=L_{b}=L_{c}=L \\
L_{b a}=L_{b c}=L_{c a}=M=0 \\
{\left[\begin{array}{l}
V_{a} \\
V_{b} \\
V_{c}
\end{array}\right]=R\left[\begin{array}{l}
i_{a} \\
i_{b} \\
i_{c}
\end{array}\right]+L p\left[\begin{array}{l}
i_{a} \\
i_{b} \\
i_{c}
\end{array}\right]+\left[\begin{array}{l}
e_{a} \\
e_{b} \\
e_{c}
\end{array}\right]+\left[\begin{array}{l}
V_{n} \\
V_{n} \\
V_{n}
\end{array}\right]}
\end{gathered}
$$

The trapezoidal Back EMF of no conducting phases,

$$
\begin{gathered}
e_{a}=K_{e} f\left(\theta_{e}\right) \omega_{r} \\
e_{b}=K_{e} f\left(\theta_{e}-\frac{2 \pi}{3}\right) \omega_{r} \\
e_{c}=K_{e} f\left(\theta_{e}+\frac{2 \pi}{3}\right) \omega_{r}
\end{gathered}
$$

The electromagnetic torque is given by,

$$
T_{e}=\frac{e_{a} i_{a}+e_{b} i_{b}+e_{c} i_{c}}{\omega_{r}}
$$

The equation of a motor for a simple system with inertia $\mathrm{J}$, friction co-efficient $\mathrm{B}$ and load torque $T_{L}$ is given by,

The output power is given by,

$$
\begin{aligned}
& T_{e}=T_{L}+J \frac{d \omega}{d t}+B \omega \\
& T_{e}=K_{t} I
\end{aligned}
$$

$$
P=T_{e} \omega_{r}
$$

The parameters R, B, J are influence the speed response of the Brushless DC motor.

\section{EXTENDED KALMAN FILTER FOR SPEED ESTIMATION}

It is all order stochastic observer for the recursive optimum state estimation of a non-linear dynamic system in real time by single signal that are corrupted by noise. The EKF can also be used for unknown parameter estimation or joint state and parameter estimation. The speed adaptive flux observer is a deterministic observer in comparision with the EKF, and is applicable to linear time invariant system. 


\section{PROPOSED SENSORLESS SPEED CONTROL OF BLDC MOTOR}

The proposed method is based on the fact that rotor position can be detected by using a trapezoidal Back-EMF of BLDC motors. Since Back-EMF of the BLDC motor is not measured directly, it is estimated by the comparator with ZCP detection technique and fuzzy logic intelligent controller is used for efficient speed control as shown in the Figure 4.

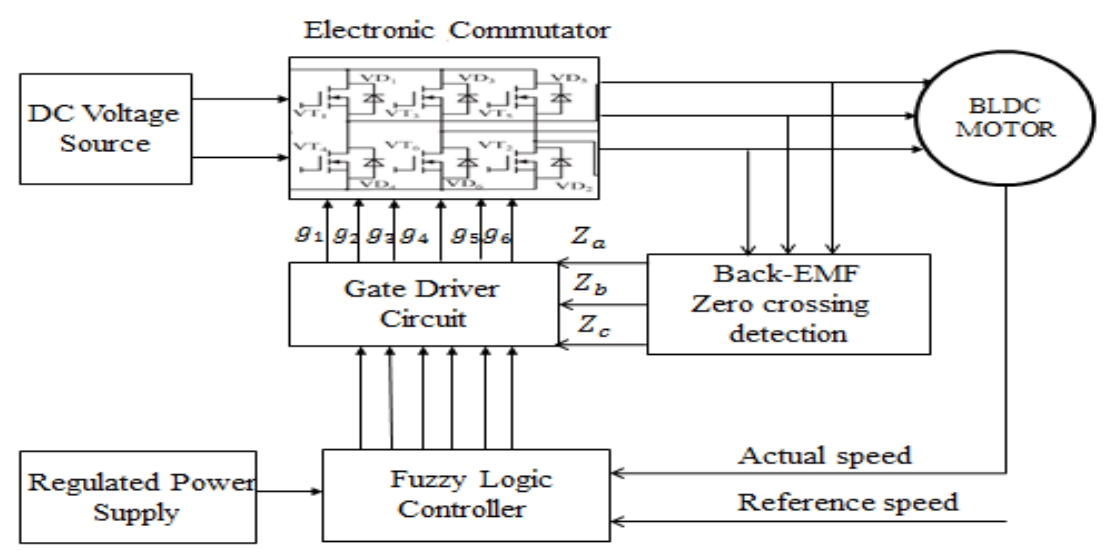

Fig. 5 Proposed block diagram of sensorless speed control of BLDC motor.

\section{A. Sensing Back EMF}

The comparator with zero cross detection technique is achieved by sensing the back EMF. The back EMF sensing is based on the information that only two phases of a BLDC motor are connected at a time and the third phase is presented to note the back EMF voltage. Consider phase $\mathrm{C}$ as floating for a particular step,

$$
V_{c}=e_{c}+V_{n}
$$

Where, $V_{c}$ is the terminal voltage of the phase C, $e_{c}$ is the phase Back EMF and $V_{n}$ is the neutral voltage of the motor.

From phase A, the term for neutral voltage is expressed as,

$$
V_{n}=V_{d c}-V_{M O S}-R_{i}-L \frac{d i}{d t}-e_{a}
$$

From phase B, the equation turns out to be,

$$
V_{n}=V_{M O S}+R_{i}+L \frac{d i}{d t}-e_{a}
$$

Where, $V_{M O S}$ is the voltage drop on MOSFET.

From equation (16) and (17),

$$
V_{n}=\frac{V_{d c}}{2}-\frac{\left(e_{a}+e_{b}\right)}{2}
$$


Considering a three-phase system by neglecting the third harmonics,

$$
e_{a}+e_{b}+e_{c}=0
$$

And the terminal voltage $V_{c}$,

$$
V_{c}=\frac{3 e_{c}}{2}+\frac{V_{d c}}{2}
$$

From equation (15) to (20), it is to be noted that the terminal voltage of the floating phase of PWM is directly proportional to the back EMF voltage plus the half of dc bus voltage.

In proposed method, the comparators are used for generating the gating signals, by comparing $V_{a}, V_{b}$ and $V_{c}$ to $V_{n}$. If $V_{a}$ is greater than $V_{n}$, then the comparator outputs high level, else the comparator outputs low level, which is expressed as $Z_{a}$ as shown in Fig. 4. At the rising edge of $Z_{a}$, the MOSFET $Q_{1}$ should be ON, and the MOSFET $Q_{5}$ should be OFF, at the falling edge of $Z_{a}$, the MOSFET $Q_{4}$ should be ON, and the MOSFET $Q_{2}$ should be OFF. Similarly, according to the rising and falling edge of $Z_{b}$ and $Z_{c}$ respectively, the other commutation instants should be obtained. The gating signals $Z_{a} \quad Z_{b}$ and $Z_{c}$ are generated from the every commutation instants. Consequently, the BLDC motor could work normally on the prior state which is obtained from the switching table.

\section{Design of Fuzzy Controller}

The generated signals are employed in fuzzy controller and reference current controller which in gate driver circuit is produced for control system as shown in Fig. 4. The current control loop regulates the BLDC motor current to the reference current value generated by the speed controller. Fig. 5 shows the basic structure of a fuzzy logic controller. The fuzzy controller is composed of the following four elements fuzzification, fuzzy rule-base, fuzzy inference engine and defuzzification.

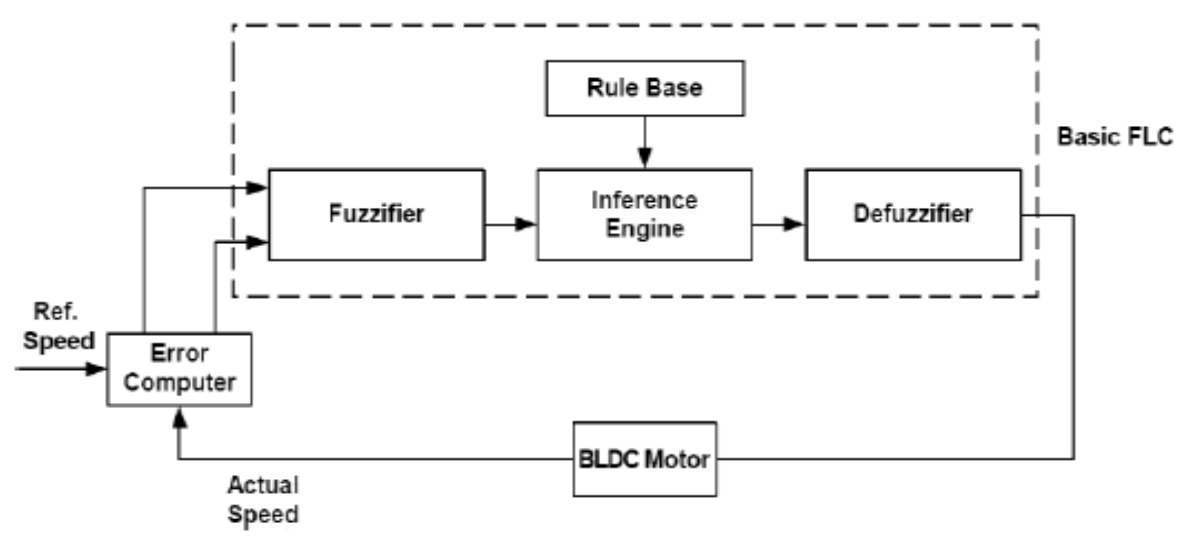

Fig. 6 Basic structure of FLC with BLDC motor. 
Error (e) and change in error (ce) are the inputs for the fuzzy controller whereas the output of the controller is change in duty cycle $(\Delta \mathrm{dc})$. The error is defined as the difference between the reference speed and actual speed, the change in error is defined as the difference between the present error and previous error and the output, the Change in duty cycle which could be either positive or negative and added with the existing duty-cycle to determine the new duty-cycle.

Fuzzy logic uses linguistic variables instead of numerical variables. The process of converting a numerical variable in to a linguistic variable is called fuzzification. Fuzzy logic linguistic terms are most often expressed in the form of logical implications, such as If-Then rules. These rules define a range of values known as fuzzy membership functions [7]. Fuzzy membership functions may be in the form of a triangle, a trapezoid or a bell.

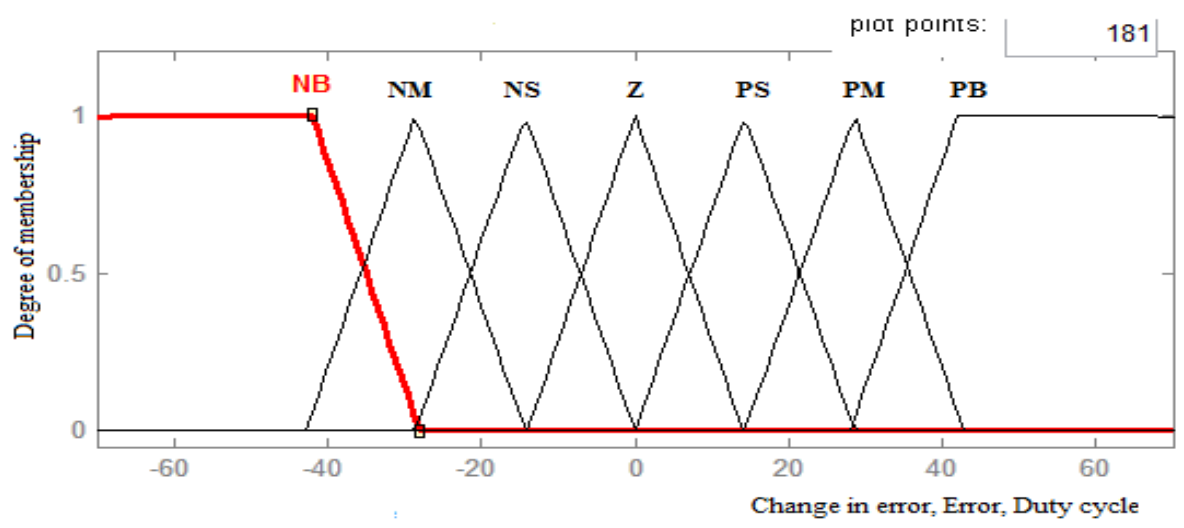

Fig. 7 Membership functions of fuzzy controller.

Fig. 7 illustrates the membership function of fuzzy logic controller that used in fuzzification of two input values and defuzzification output of the controller. There are seven clusters in the membership functions, with seven linguistic variables defined as Negative Big (NB), Negative Medium (NM), Negative Small (NS), Zero (Z), Positive Small (PS), Positive Medium (PM), and Positive Big (PB). Fig 8 shows the MATLAB simulation diagram of fuzzy logic controller.

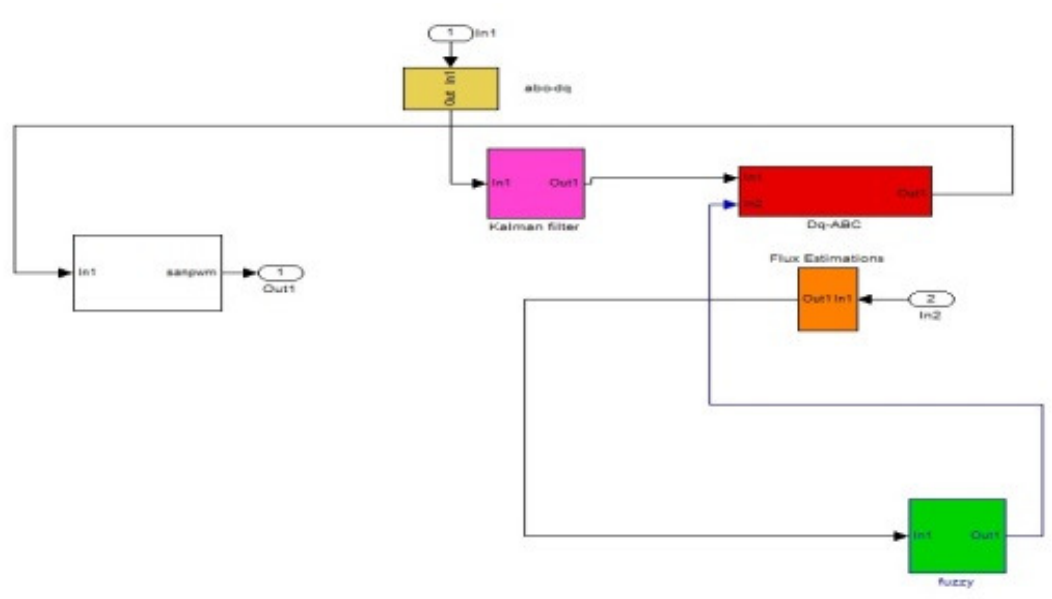

Fig. 8 Matlab simulation diagram of fuzzy logic control. 
A sliding mode rule-base, used in the fuzzy logic controller is given in Table I. The fuzzy inference operation is implemented by using the 49 rules.

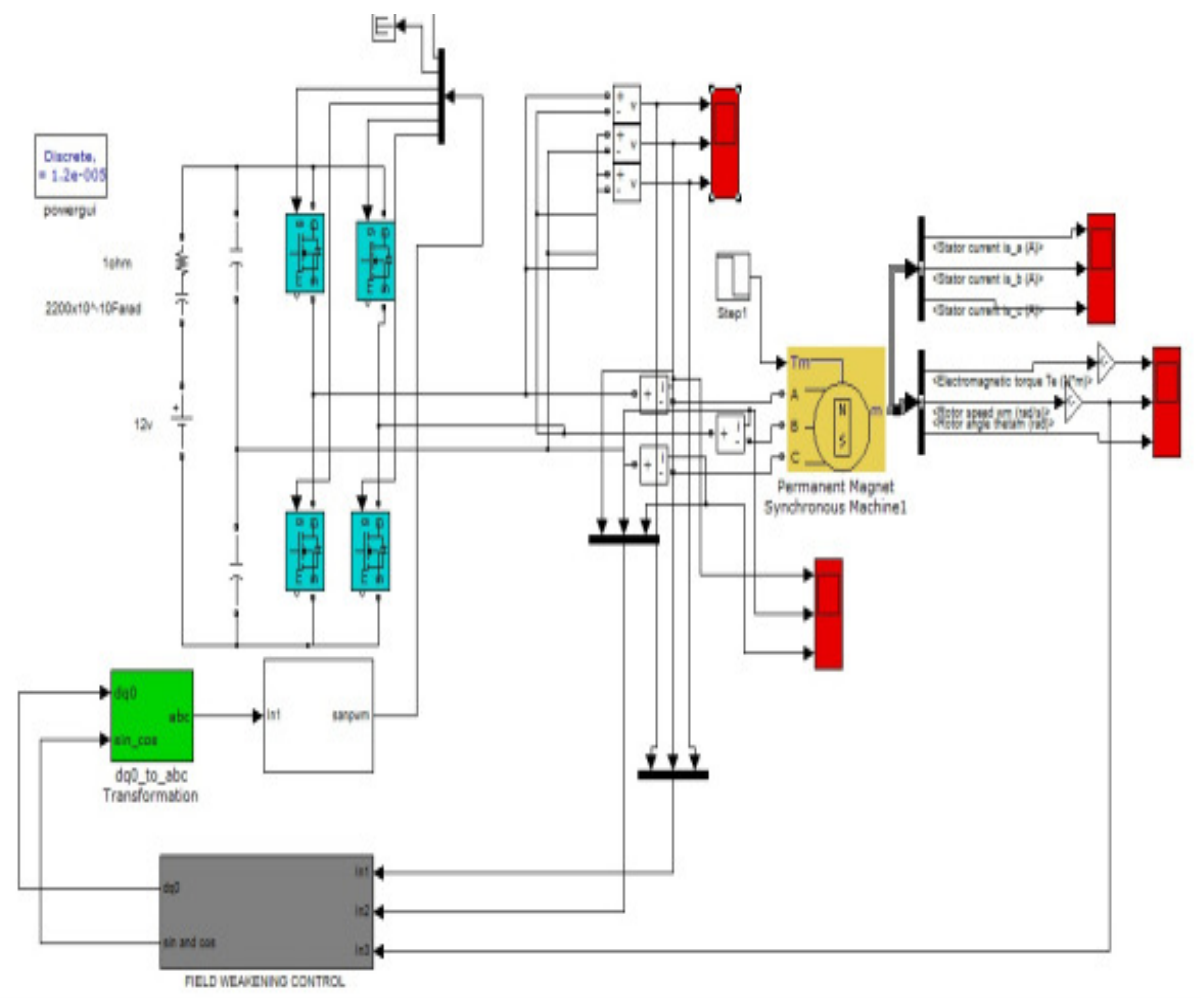

Fig. 9 Simulation diagram of proposed sensorless speed control of BLDC motor

The min-max compositional rule of inference and the center of gravity method have been used in the defuzzification process. The developed MATLAB model shown in the Fig. 8 is use to observe the phase current waveforms, back-EMF, speed and torque to assigned motor specification shown in Table II

TABLE I FUZZY RULE BASE

\begin{tabular}{|l|l|l|l|l|l|l|l|}
\hline $\begin{array}{l}\text { Change } \\
\text { in error }\end{array}$ & \multicolumn{7}{|c|}{ Error } \\
\cline { 2 - 8 } & NB & NM & NS & Z & PS & PM & PB \\
\hline NB & NB & NB & NB & NB & NM & NS & Z \\
\hline NM & NB & NB & NB & NM & NS & Z & PS \\
\hline NS & NB & NB & NM & NS & Z & PS & PM \\
\hline Z & NB & NM & NS & Z & PS & PM & PB \\
\hline PS & NM & NS & Z & PS & PM & PB & PB \\
\hline PM & NS & Z & PS & PM & PB & PB & PB \\
\hline PB & Z & PS & PM & PB & PB & PB & PB \\
\hline
\end{tabular}


TABLE II MOTOR SPECIFICATIONS FOR SIMULATION

\begin{tabular}{|c|c|}
\hline $\begin{array}{l}\text { SIMULATION } \\
\text { PARAMETERS }\end{array}$ & VALUES \\
\hline \multicolumn{2}{|c|}{ BLDC MOTOR PARAMETERS } \\
\hline Power & $3 \mathrm{hp}$ \\
\hline Voltage & $12 \mathrm{v}$ \\
\hline Current & $0.8 \mathrm{a}$ \\
\hline Speed & 1500rpm \\
\hline Frequency & $60 \mathrm{hz}$ \\
\hline Pole pairs & 1 \\
\hline Inertia & $8 \times 10^{-3} \mathrm{~kg} \mathrm{~m}^{2}$ \\
\hline Stator phase resistance & $2.8750 \mathrm{ohm}$ \\
\hline Stator phase inductance & $8.5 \times 10^{-3}$ henrys \\
\hline Flux linkage & $0.175 \mathrm{vs}$ \\
\hline \multicolumn{2}{|c|}{ PI CONTROLLER PARAMETERS } \\
\hline Proportional gain & 0.1 \\
\hline Integral gain & 1 \\
\hline \multicolumn{2}{|c|}{ FUZZY CONTROLLER PARAMETERS } \\
\hline Proportional gain & 180 \\
\hline Integral gain & 3200 \\
\hline
\end{tabular}

\section{SIMULATION RESULTS AND DISCUSSIONS}

In order to validate the control strategies as described, digital simulations were carried out on a converter for the BLDC motor drive system using MATLAB/SIMULINK, where the parameters used for the DC motor drive system is given in Table II. Simulation studies were carried out to evaluate the performance of sensorless based speed control of BLDC motor. Here the speed is controlled without sensors.

Fig 10(a) represents about speed response using PI controller here the speed achieved is 1500rpm and where as in fuzzy $900 \mathrm{rpm}$ is achieved, by keeping fuzzy as conventional pi is used as proposed controller. Fig 11(a) represents torque using PI, Fig 11(b) represents torque using Fuzzy 


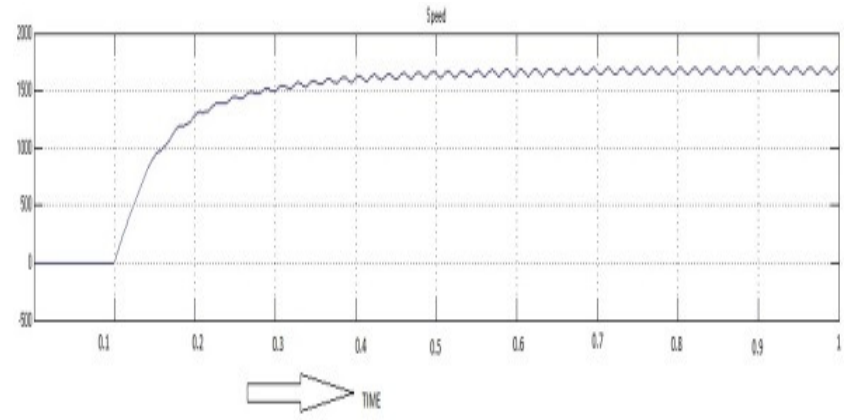

Fig. 10(a) Speed response using PI

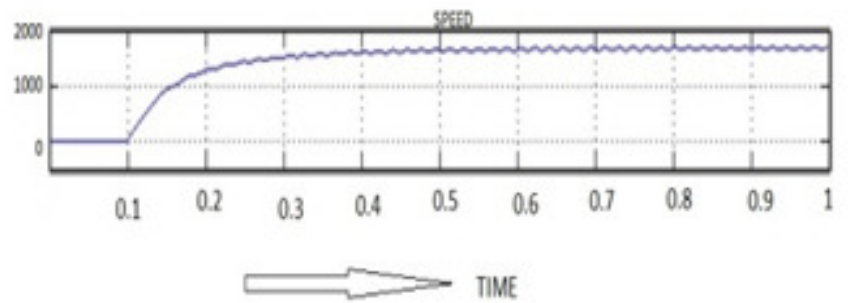

Fig. 10(b) Speed response using Fuzzy.

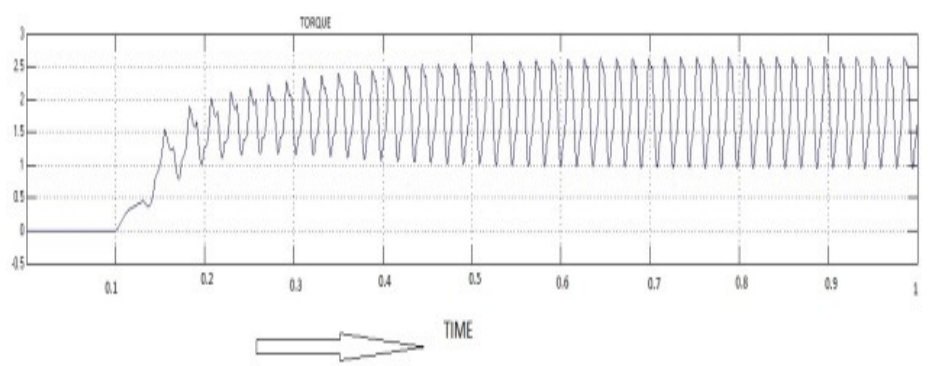

Fig. 11(a) Torque response using PI with reference set speed 1500rpm.

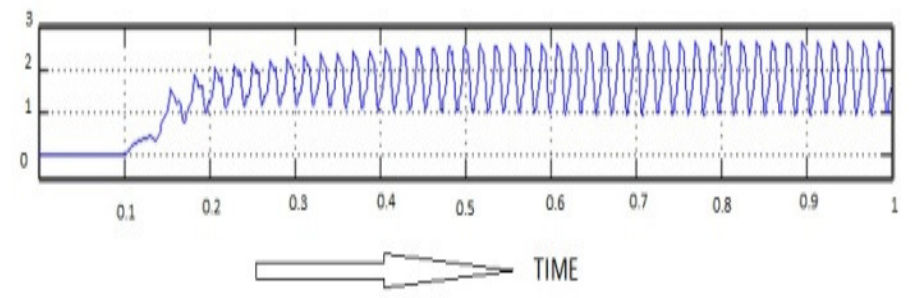

Fig. 11(b) Torque response using Fuzzy with reference set speed 1500rpm.

Comparison results:

\begin{tabular}{|l|l|l|l|}
\hline PARAMETER & TIME & PI & FUZZY \\
\hline Speed (rpm) & 0.4 & 1500 & 900 \\
\hline Torque(nm) & 0.175 & 0.2 & 1.5 \\
\hline
\end{tabular}


Comparative study analysis:

\begin{tabular}{|l|l|l|l|}
\hline \multicolumn{5}{|c|}{ SPEED USING PI } \\
\hline Set speed & Settling time & Rising time & Output speed \\
\hline 1500 & 0.4 & 0.3 & 1500 \\
\hline 500 & 0.3 & 0.2 & 480 \\
\hline 100 & 0.25 & 0.1 & 100 \\
\hline \multicolumn{5}{|c|}{ SPEED USING FUZZY } \\
\hline 1500 & 0.2 & 0.25 & 800 \\
\hline 500 & 0.25 & 0.15 & 500 \\
\hline 100 & 0.27 & 0.1 & 100 \\
\hline
\end{tabular}

\begin{tabular}{|l|l|l|}
\hline \multicolumn{3}{|c|}{ TORQUE USING PI } \\
\hline 1500 & 0.4 & 0.1 \\
\hline 500 & 0.35 & 0.15 \\
\hline 100 & 0.1 & 0.17 \\
\hline \multicolumn{3}{|c|}{ TORQUE USING FUZZY } \\
\hline 1500 & 0.3 & 0.15 \\
\hline 500 & 0.2 & 0.1 \\
\hline 100 & 0.1 & 0.005 \\
\hline
\end{tabular}

\section{CONCLUSIONS}

Sensorless speed control of BLDC motor drive with PI logic implementation based on comparator with zero crossing detection have been experimented using MATLAB and evaluation of results are observed. The simulation results have shown that speed response of the BLDC motor can be controlled without sensors and also reduces the torque ripple. The results obtained from sensorless speed control of BLDC motor demonstrates that the system is less cost compared to sensored control and also good dynamic performance is obtained. This makes the motor suitable in application such as fuel pump, robotics and industrial automation. The proposed speed control scheme is robust, efficient and easy to implement in place of sensored applications.

\section{REFERENCES}

[1] Nobuyuki Matsui, "Sensorless PM Brushless DC Motor Drives", IEEE Trans. on Industrial Electronics, Vol.43, No.2,pp.300-308, April 1996.

[2] Champa.P, Somasiri.P, Wipauramonton.P and Nakmahachalasint.P, "Initial Rotor Position Estimation for Sensorless Brushless DC Drives", IEEE Trans. on Ind. Applications, Vol.45,No.4, pp.1318-1324,July 2009. 
[3] Somanatham.R, Prasad.P.V.N, Rajkumar.A.D, "Modelling and Simulation of Sensorless Control of PMBLDC Motor Using Zero Crossing Back EMF Detection" IEEE SPEEDAM 2006 International Symposium on Power Electronics, Drives, Automotive and Motion.

[4] Bimal K Bose, "Modern Power Electronics and AC Drives", Pearson Education Asia 2002.

[5] Miller. T.J.E., "Brushless permanent magnet and reluctance motor drives ", Clarendon Press, Oxford, 1989.

[6] Ramesh.M.V, Amarnath.J, Kamakshaiah.S and Rao.G.S, "Speed control of Brushless DC Motor by using Fuzzy Logic PI Controller", ARPN Journal of Engineering and Applied Sciences, Vol.6, No.9, September 2011.

[7] Yan Wei-Sheng, Lin Hai, Li Hong,Yan Wei, "Sensorless Direct Torque Controlled Drive of Brushless DC Motor based on Fuzzy Logic", IEEE Trans. on Ind. Elec. and Appl., Vol.23, No.4, July 2009.

[8] Taeyeon Kim, Chungil Kim, Joon Lyou, "A New Sensorless Scheme for a BLDC Motor Based on the Terminal Voltage Difference" IEEE Trans. on Industrial Applications, Vol.6, No.7, pp.1710-1715, September 2011.

[9] Anjali A.R, Calicut University, "Control of Three Phase BLDC Motor Using Fuzzy Logic Controller", International Journal of Engineering Research \& Technology (IJERT) ISSN: 2278-0181, Vol.2, Issue 7, July 2013.

[10] Bindu V, Unnikrishnan A, Gopikakumari R, "Fuzzy logic based sensorless vector control of Induction motor", IEEE Trans. Ind. Appl., Vol.39, No. 6, Feb 12, 2012. 